\title{
Study on the Civil Law Responsibility of the Network Car Platform Company
}

\author{
Han Xiao \\ Wuhan Engineering Institute, Wuhan, Hubei, 430415
}

Keywords: Network Car Platform, Civil Law Responsibility, Social Management

\begin{abstract}
This paper mainly analyzes the content of the regulations related to the network car management, and expounds the essential difference between the network car platform company and the cruise taxi service company. The current regulations locating the network car platform company as a taxi service company have many defects. The network car platform company mainly provides network information service in the network car service. The current management regulations have many problems in positioning it as a carrier. The labor relationship between the network car platform company and the vehicle provider is also determined. The facts do not match the legal principles.
\end{abstract}

\section{Introduction}

There are mainly H modes in the current network: one is the self-operated "special car mode". In this mode, the vehicle is provided by a car rental company or the network platform is purchased and affiliated with the leasing company. This mode is in the development network. In the early stage of the car development, it was widely adopted in order to avoid legal supervision. The second is the inter-type "fast mode". In this model, the information provider of the network platform W provides information and cooperation for the passengers and the private car drivers of the access platform. This model is for private cars and traditional taxis. the Lord. The Hth is the "winding" mode. In this mode, the role played by the network platform is similar to that of the intervening mode. It is only responsible for exchanging information of all parties, but it is slightly different in the way of travel. The self-operated "special car mode" is not a for-profit service provider. The "winding" model is not a business act. In order to share the personal expenses of travel expenses, the responsibility of each party in this mode can be distributed through existing laws and regulations. Among the many models, the most common and controversial is the intermediaries type of "fast mode". Therefore, the focus of this paper is on the research and discussion on the subject positioning and responsibility of the network car platform in the "fast mode". .

\section{Network car platform company's business positioning}

Talking about the network car is very easy to be confused with the taxi car cruising. It is also a passenger service but it has absolute differences. This difference is concentrated in the business model of the network car platform company and the taxi service company. First, the network car platform company and the taxi service company have different forms of participation in the passenger service; the network car platform company's business activities are mainly in the exchange of information between the vehicle provider and the passenger, through the Internet information, based on the passenger specific The demand for passengers to screen out the most suitable vehicles, so that LJ can see that the network car platform is deeply involved in every operation service. The taxi service company will not participate in the specific passenger service. Its main work focuses on the overall control of the driver and the vehicle, and does not participate in specific contracting activities. Second, the basis for forcing service providers to provide services is different. Traditional parade taxis, as a supplement to public transportation, cannot reject passengers' reasonable carriage requirements, which is based on the characteristics of the administrative concession industry. The taxi service company fulfills this compulsory through the company's internal management regulations, which becomes the management right of the taxi 
service company. The network car platform company mandatory for the vehicle provider to carry out the specific order service is based on the agreement between the two parties when accessing the platform, not because of the internal management regulations of the network car platform company, in other words, the network car platform company It is based on the rights of the contract. In the H, the actual managers of the service vehicles in the business process are different. The service vehicles in the traditional cruise taxi mode are owned or leased by the taxi service company, and the taxi service company has absolute control over the vehicle. The service vehicle in the network-about vehicle mode is all the consuming property owned by the vehicle provider, and the network-based vehicle platform cannot perform arbitrary control. Fourth, the labor relationship with the driver is different. In the traditional cruise taxi, the taxi service company and the driver have a pure labor relationship, and the driver is a duty behavior in the service process. The network car platform company does not necessarily establish a labor relationship with the vehicle provider. Even if the labor contract is signed, there is no actual labor relationship. The vehicle providers of the network car model are mostly part-time, and for the vehicle supplier, I don't think I have a labor relationship with the network car platform company. In summary, in the actual business process, the network car platform company and the taxi service company are completely different subjects.

\section{Definition of the joint operation relationship betweennetwork car platform companies and service vehicle providers}

The establishment of labor relations is mainly based on the main characteristics, the subordinate attribute $\mathrm{W}$ and the labor $\mathrm{H}$ element in the judicial practice of our country. The main feature is that both parties are required to have the subject qualification in civil law. Net car platform companies and vehicle providers clearly have the main features. In the analysis of whether there is a dependency problem, management standards, compensation methods, and production factor standards are usually considered. In the weaving mode of the network car, the vehicle provider is subject to the constraint management of the network car platform company to a certain extent, and the service cost is also issued by the network car platform company, and the vehicle provider is in the service process. The use of the production materials of the network car platform company also meets the standards of production factors. In the course of service, the vehicle provider also adopts the form of salary exchange through labor behavior and also satisfies the conditions of labor factors. But the labor law that emerged as an industrial era clearly cannot take into account the problems that arise in the sharing economy. As far as the main features are concerned, the way in which the network car platform company and the vehicle provider are hired is not a traditional form, but a qualification review through the network. The network car platform cannot refuse to access the vehicle provider without justification. The attribute aspect is also different from the traditional form. The vehicle provider has greater independence and work autonomy, and the dependence on the network car platform is weakened. Even the network car platform needs to attach a large number of vehicles to a certain extent. The provider can operate normally.

\section{Analysis of Civil Liability of 3 Network Car Platform Company}

The prosperity of the network car until the officially recognized process, it is more worthy of our vigilance is how to solve the problem of responsibility of the network car platform company under the current regulations. According to the "Interim Measures", "the network car platform company bears the carrier's responsibility, it should ensure the safety of operations and protect the legitimate rights and interests of passengers." This indicates that the network car platform should be responsible for the network car service. When a party defaults, it is worthwhile to discuss what kind of responsibility the network car platform and vehicle provider should bear. The rules of Beijing, Shenzhen and other places also stipulate that the network car platform company bears all carrier responsibility. Beijing's rules clearly state that this responsibility includes the responsibility of the contract of carriage. There is a stereotyped cooperative relationship between the network car platform company and the vehicle provider. The transportation relationship is based on the format 
clause of the vehicle provider access network. The terms and conditions govern the actions of both parties. When there is a violation of the terms by both parties, the parties shall bear the contractual liability in accordance with the terms and conditions. Since the vehicle provider and the network car platform company are in a cooperative relationship, both parties should have their own meanings when participating in the business problem, but in the specific service process, the network car platform is forced to promote the driver. The behavior of the order does not give the vehicle provider the opportunity to fully negotiate with the passenger. When this happens and the network car platform company damages the interests of the vehicle provider, the vehicle provider may exclude the main right of the contract clause from the invalidity of the contract terms. Of course, this is only when the behavior of the mandatory delivery order of the network car platform company actually damages the rights of the vehicle provider. It is impossible to require all vehicle providers and passengers to conduct full consultations, which will affect the efficiency of the industry and increase the operation. the cost of. Therefore, in the actual business service, if the passenger does not have special requirements and the forced push order does not damage the actual interests of the vehicle provider, T should follow the cooperation contract between the network platform company and the vehicle provider. To constrain the behavior of both, bear the contractual responsibility for the breach of contract.

In the process of network car service, the mandatory contracting behavior of the network car platform company did not give the driver and passengers full opportunity to negotiate. In this case, the passenger's intention when placing an order indicates that there is no requirement other than transporting the passenger. At this time, the passenger's order is a complete meaning after completing the start and stop information. As an invitation to the contract of transportation, it is logical. In principle, the network platform is not the manager of the vehicle and the driver. However, in the actual operation process, the network platform is qualified for the actual deployment and commitment of the overall operational resources, then the contract should be established when the network platform accepts and confirms the passenger order. Therefore, although the network car platform company does not carry out specific transportation activities, it can be recognized as a common business service provider because of its cooperation with the vehicle supplier. In the process of contracting with passengers, the meaning of the network car platform company is also reflected in it, which indicates that there is also a contractual relationship between the network car platform company and the passengers. For the passengers, the network car platform company and the vehicle provider are integrated, and they are the relatives of the passenger contract, but the responsible transportation links are different. In reality, the withdrawal behavior of the network car platform company or the vehicle provider's failure to perform the contract is often established. The service contract has been established when the network car platform company accepts the order. The withdrawal of the $\mathrm{W}$ and the non-compliance are all in the act. The act after the establishment of the contract shall be deemed to be a breach of contract, and because it is the common body of the service, the liability for breach of contract shall be jointly assumed for the passenger. Another situation is the passenger's breach of contract, and passengers may have problems with no fees. At this point, the service party has fulfilled the contractual obligations, and the passenger's breach of contract is subject to the service contract. The main meaning of the service contract is the passenger and network car platform, and the technology of the network car platform is considered. The advantage of resources, this kind of accountability should be handed over to the network car platform company. For the loss of the vehicle provider that does not substantially participate in the contract formation process, it should be paid by the network car platform company first.

\section{Conclusion}

The network car service based on the development of Internet information technology is changing the pattern of the taxi industry through technical means. Reasonable distribution of limited transportation resources through information technology has effectively solved the shortcomings of poor communication of traditional parade taxi information, and mobilized idle transportation resources of the society has also effectively solved problems such as traffic congestion and waste of 
resources. There are still many problems to be solved in the development of the industry. This paper analyzes the positioning, responsibility distribution and existing departments of the network car platform under the new situation. Provided pertinent suggestions for the operation of the network car service, and envisaged another system design for the network car platform company, thus ensuring the safe and orderly operation of the carrier in maintaining the basic field of the rights of the driver, passengers and the network car platform.

\section{Acknowledgement}

Fund Project: Technical Research Project of Hubei Provincial Department of Education (NO.B2018526), network car Platform Company's business positioning and legal responsibility.

\section{References}

[1] Gu Dasong. Car legislation and discussion [J]. Administrative Jurisprudence, 2016 (2).

[2] Zhang Dongyang. Car service: institutional innovation or illegal behavior [A]. Tsinghua Law, 2016.

[3] Fu Weigang. Is car legislation promoting innovation? [J]. Financial Law, 2016 (2).

[4] Xiong Bingwan. A new exploration of car carpooling control [JL Tsinghua Law, 2016 (2).

[5] Wu Dao. The institutional logic of the network about taxi supervision [J] Finance and Economics Law, 2016 (02) 